\title{
EXISTENCE OF SOLUTIONS FOR SOME DEGENERATE SEMILINEAR ELLIPTIC EQUATIONS WITH MEASURE DATA
}

\author{
ARUN KUMAR BADAJENA and SHESADEV PRADHAN
}

Abstract. We study the existence of a weak solution for the degenerate semilinear elliptic problem

$$
\begin{aligned}
-\sum_{i, j=1}^{n} \mathrm{D}_{j}\left(a_{i j}(x) \mathrm{D}_{i} u(x)\right)-\lambda g(x) u(x) & =-f(x, u(x))+\mu \quad \text { in } \Omega \\
u & =0 \quad \text { on } \partial \Omega,
\end{aligned}
$$

where $\Omega$ is a bounded open subset of $\mathbb{R}^{N}, N \geq 2$ and $\lambda$ is a real parameter. Here $g: \Omega \rightarrow \mathbb{R}$ and $f: \Omega \times \mathbb{R} \rightarrow \mathbb{R}$ are functions satisfying suitable hypotheses and $\mu$ is a Radon measure.

MSC 2010. 35J70, 47H05.

Key words. Degenerate semilinear elliptic equations, monotone operators, measure data.

\section{REFERENCES}

[1] F. Antoci, Some necessary and some sufficient conditions for the compactness of the embedding of weighted Sobolev spaces, Ric. Mat., 52 (2003), 55-71.

[2] A.C. Cavalheiro, Existence of solutions for the Dirichlet problem of some degenerate semilinear elliptic equations, Appl. Math. Lett., 23 (2010), 317-208.

[3] F. Browder, Nonlinear elliptic boundary value problems, Bull. Amer. Math. Soc., 69 (1963), 862-874.

[4] E. Fabes, D. Jerison and C. Kenig, The Wiener test for degenerate elliptic equations, Ann. Inst. Fourier, 32 (1982), 151-182.

[5] E. Fabes, C. Kenig and R. Serapioni, The local regularity of solutions of degenerate elliptic equations, Comm. Partial Differential Equations, 7 (1982), 77-116.

[6] B. Franchi and R. Serapioni, Pointwise estimates for a class of strongly degenerate elliptic operators: A geometrical approach, Ann. Sc. Norm. Sup. Pisa Cl. Sci., 14 (1987), $527-568$.

[7] J. Garcia-Cuerva and J.L. Rubio de Francia, Weighted norm inequalities and related topics, North-Holland Mathematics Studies, Vol. 116, Amsterdam, 1985.

[8] J. Heinonen, T. Kilpeläinen and O. Martio, Nonlinear potential theory of degenerate elliptic equations, Oxford Math. Monogr., Clarendon Press, Oxford, 1993.

[9] A. Kufner, O. John, and S. Fučik, Functions Spaces, Noordhoff International Publishing, Leyden, 1977.

The authors thank the referee for his helpful comments and suggestions.

DOI: 10.24193/mathcluj.2021.1.03 
[10] B. Muckenhoupt, Weighted norm inequalities for the Hardy maximal function, Trans. Amer. Math. Soc., 165 (1972), 207-226.

[11] A. Torchinsky, Real-Variable Methods in Harmonic Analysis, Academic Press, San Diego, 1986.

[12] B. O. Turesson, Nonlinear potential theory and weighted Sobolev spaces, Lecture Notes in Mathematics, Vol. 1736, Springer-Verlag, Berlin, 2000.

[13] K. Yosida, Functional analysis, 6th edition, Springer-Verlag, Berlin/New York, 1980.

[14] E. Zeidler, Nonlinear Functional analysis and its Applications, Part II, Springer-Verlag, New York, 1990.

Received July 17, 2019

Accepted November 11, 2019

\author{
National Institute of Technology Rourkela \\ Department of Mathematics \\ Odisha, India \\ E-mail: ons.arun93@gmail.com \\ https://orcid.org/0000-0001-5637-8510 \\ E-mail: shesadevpradhan@gmail.com \\ https://orcid.org/0000-0002-1476-6301
}

